\title{
Hydrogen sulfide improves neural function in rats following cardiopulmonary resuscitation
}

\author{
JI-YAN LIN $^{1 *}$, MIN-WEI ZHANG ${ }^{1 *}$, JIN-GAO WANG $^{1}$, HUI LI $^{2}$, HONG-YAN WEI ${ }^{2}$, \\ RONG LIU ${ }^{2}$, GANG DAI ${ }^{3}$ and XIAO-XING LIAO ${ }^{2}$ \\ ${ }^{1}$ Department of Emergency and Critical Care Medicine, The First Affiliated Hospital of Xiamen University, Xiamen, \\ Fujian 361003; ${ }^{2}$ Department of Emergency, The First Affiliated Hospital of Sun-Yat Sen University; \\ ${ }^{3}$ Key Laboratory on Assisted Circulation, Ministry of Health, Sun Yat-Sen University, \\ Guangzhou, Guangdong 510080, P.R. China
}

Received August 1, 2014; Accepted May 1, 2015

DOI: $10.3892 /$ etm.2015.2950

\begin{abstract}
The alleviation of brain injury is a key issue following cardiopulmonary resuscitation (CPR). Hydrogen sulfide $\left(\mathrm{H}_{2} \mathrm{~S}\right)$ is hypothesized to be involved in the pathophysiological process of ischemia-reperfusion injury, and exerts a protective effect on neurons. The aim of the present study was to investigate the effects of $\mathrm{H}_{2} \mathrm{~S}$ on neural functions following cardiac arrest (CA) in rats. A total of 60 rats were allocated at random into three groups. CA was induced to establish the model and CPR was performed after $6 \mathrm{~min}$. Subsequently, sodium hydrosulfide (NaHS), hydroxylamine or saline was administered to the rats. Serum levels of $\mathrm{H}_{2} \mathrm{~S}$, neuron-specific enolase (NSE) and S100 $\beta$ were determined following CPR. In addition, neurological deficit scoring (NDS), the beam walking test (BWT), prehensile traction test and Morris water maze experiment were conducted. Neuronal apoptosis rates were detected in the hippocampal region following sacrifice. After CPR, as the $\mathrm{H}_{2} \mathrm{~S}$ levels increased or decreased, the serum NSE and S100 $\beta$ concentrations decreased or increased, respectively $(\mathrm{P}<0.0 \mathrm{w}$. The NDS results of the NaHS group were improved compared with those of the hydroxylamine group at $24 \mathrm{~h}$ after CPR $(\mathrm{P}<0.05)$. In the Morris water maze experiment, BWT and prehensile traction test the animals in
\end{abstract}

Correspondence to: Professor Ji-Yan Lin, Department of Emergency and Critical Care Medicine, The First Affiliated Hospital of Xiamen University, 55 Zhenhai Road, Xiamen, Fujian 361003, P.R. China

E-mail: ljcndoc@163.com

Professor Xiao-Xing Liao, Department of Emergency, The First Affiliated Hospital of Sun Yat-Sen University, 58 Zhongshan 2nd Road, Guangzhou, Guangdong 510080, P.R. China

E-mail: liaowens@163.com

*Contributed equally

Key words: cardiopulmonary resuscitation, apoptosis, brain injury, neurological behavior, hydrogen sulfide the NaHS group performed best and rats in the hydroxylamine group performed worst. At day 7, the apoptotic index and the expression of caspase- 3 were reduced in the hippocampal CA1 region, while the expression of $\mathrm{Bcl}-2$ increased in the NaHS group; and results of the hydroxylamine group were in contrast. Therefore, the results of the present study indicate that $\mathrm{H}_{2} \mathrm{~S}$ is able to improve neural function in rats following CPR.

\section{Introduction}

Brain damage following cardiac arrest (CA) is typically the result of ischemic or hypoxic injury in vulnerable areas of the brain, such as the hippocampus, cortex and thalamus, and triggers a series of pathophysiological processes following $\mathrm{CA} /$ cardiopulmonary resuscitation (CPR). The necrosis and apoptosis of numerous nerve cells leads to various neuronal dysfunctions, including anterograde amnesia, learning difficulties, emotional and social behavioral changes, depression, and potentially coma, persistent vegetative state and mortality. Thus, brain damage has been considered to be a major sign of post-CA syndrome, which often increases the mortality rate in addition to the effects caused by the primary diseases that induce CA (1). Effective attenuation of brain injury is one of the key aims of CPR.

As the third gaseous signaling molecule in vivo, hydrogen sulfide $\left(\mathrm{H}_{2} \mathrm{~S}\right)$ has a relatively small molecular mass, which allows it to traverse the cell membrane freely without requiring a receptor. Previous studies have indicated that $\mathrm{H}_{2} \mathrm{~S}$ is involved in the pathophysiological process of ischemia-reperfusion injury and shock, and exerts protective effects on neurons (2-7). $\mathrm{H}_{2} \mathrm{~S}$ has been demonstrated to increase the expression of $\gamma$-aminobutyric acid $\mathrm{B}$ receptor subunits 1 and 2 , and subsequently reduce excitotoxic injury $(8,9) \cdot \mathrm{H}_{2} \mathrm{~S}$ mediates signals between neuronal cells and astrocytes by increasing the influx of $\mathrm{Ca}^{2+}$ in order to maintain calcium homeostasis and regulate synaptic activity (10). Furthermore, $\mathrm{H}_{2} \mathrm{~S}$ is known to exert protective effects on neurons via its antioxidative functions (11). However, the effects of $\mathrm{H}_{2} \mathrm{~S}$ on brain injury after $\mathrm{CA}$ are not clear and the results of previous studies appear contradictory. For example, the administration of the $\mathrm{H}_{2} \mathrm{~S}$ donor sodium 
sulfide $\left(\mathrm{Na}_{2} \mathrm{~S}\right) 1 \mathrm{~min}$ prior to $\mathrm{CPR}$ has been demonstrated to significantly improve the survival rate and neurological function of rats at $24 \mathrm{~h}$ (12) or 10 days after CPR (13). Furthermore, Derwall et al observed that high-dose $\mathrm{Na}_{2} \mathrm{~S}$ significantly reduces microglial activation in striatal areas, although this did not translate into improved neurological outcome in a porcine model of prolonged CA (14). Knapp et al reported that $\mathrm{Na}_{2} \mathrm{~S}$ therapy is associated with a temporary beneficial effect on neurological outcome (3 days after CPR) (15). Therefore, the present study aimed to clarify the modulation of $\mathrm{H}_{2} \mathrm{~S}$ levels in the serum of rats and to evaluate the effects of treatment with the $\mathrm{H}_{2} \mathrm{~S}$ donor sodium hydrosulfide (NaHS) or hydroxylamine, a cystathionine- $\beta$-synthase (CBS) inhibitor, on brain injury following $\mathrm{CA}$. These effects were evaluated by examining biomarkers of brain injury, neurologic deficit scoring (NDS) and the neural behavior after CPR. CBS is able to catalyze the synthesis of $\mathrm{H}_{2} \mathrm{~S}$ from L-cysteine in mammalian central nervous system tissues (16) and it was hypothesized that hydroxylamine application may reduce the levels of $\mathrm{H}_{2} \mathrm{~S}$.

\section{Materials and methods}

Subjects and groups. All animal procedures were approved and conducted in accordance with the Animal Ethics Committee of Sun Yat-Sen University (Guangzhou, China) and the UK Home Office Animals (Scientific Procedures) Act 1986. All procedures conformed to Directive 2010/63/EU of the European Parliament. Animal experiments were conducted in the Assisted Circulation Key Laboratory of Ministry of Health at Sun Yat-Sen University. Animals were provided by the Laboratory Animal Center of Sun Yat-Sen University.

A total of 60 healthy male Sprague-Dawley rats, aged 10-12 months old and weighing 450-550 g, were allocated at random into the NaHS, hydroxylamine or routine CPR control groups ( $n=20$ per group). The further 40 rats were used as spare rats to supplement the rats if any died prior to the end point of observation. A further 100 male rats of the same weight and brood were prepared as blood donors.

Induction of the CA model. The rat model of CA was established as described in our previous study (17). Briefly, the rats were anesthetized via a bolus intraperitoneal injection of $10 \%$ chloral hydrate $(3 \mathrm{ml} / \mathrm{kg})$. The degree of anesthesia was evaluated by measurement of muscular tone, corneal reflex and pain reflex. Tracheal intubation was performed through the mouth and cardiac monitoring was performed by electrocardiography using limb leads (V3404; SurgiVet, Inc., Waukesha, WI, USA). A $24 \mathrm{G}$ close-vein indwelling needle (BD Intima $\mathrm{II}^{\mathrm{TM}}$ Vein $^{\mathrm{TM}}$; Suzhou Becton Dickinson Medical Devices Co., Ltd., Suzhou, China) was inserted into the right femoral vein to establish a transfusion passage. A $22 \mathrm{G}$ close-vein indwelling needle was inserted into the right femoral artery. A three-way cock valve was connected to the remaining arterial needle. One end was connected to an injector with heparin, and the other end was connected to the BL-420E Biological Data Acquisition and Analysis system (Chengdu TME Technology Co., Ltd., Chengdu, China). After the chest skin of the rats was shaved, two disposable acupuncture needles (30G HuanQiu; Suzhou Acupuncture Supplies Co., Ltd., Suzhou, China) were transcutaneously inserted into the epicardium between the fourth rib of the left sternal border and the third rib of the right sternal border. The stimulator electrode of the BL-420E system was then connected, which was used to supply direct and constant electrical stimulation of the epicardium with crude current, continuous single stimulation, a delay of $100 \mathrm{msec}$, a wave width of $1 \mathrm{msec}$, a frequency of $50 \mathrm{~Hz}$, an initial intensity of 1-2 $\mathrm{mA}$ and a stimulation duration of $3 \mathrm{~min}$. CA was defined as follows (18): i) Systolic arterial pressure quickly reduced to $<25 \mathrm{mmHg}$ after electrical stimulation; ii) the arterial pulse wave from blood pressure monitoring disappeared after electrical stimulation; and iii) the electrocardiographic wave displayed on the cardiac monitor indicated ventricular fibrillation, pulseless electrical activity or asystole following the cessation of electrical stimulation.

$C P R$. CPR was performed with the Utstein style (18) following a 6-min period without any intervention. External chest compression was performed using an external chest compression machine for small animals, developed by the Key Laboratory of Assisted Circulation of Sun Yat-Sen University, at a rate of 200 compressions/min, with equal compression-relaxation, and depth of compression to $1 / 3$ of the anteroposterior chest diameter. Intermittent positive pressure ventilation was performed using a Model 683 Small Animal Ventilator (Harvard Apparatus, Inc., Holliston, MA, USA) with the initial parameters as follows: Set frequency, 70 times/min; tidal volume, $0.65 \mathrm{ml} / 100 \mathrm{~g}$; and inspired oxygen concentration, $21 \%$. Parameters for the next respirator were adjusted according to blood gas analysis. Adrenalin $(2 \mu \mathrm{g} / 100 \mathrm{~g})$ was immediately administered to the rats at the initiation of CPR and was readministered at $3 \mathrm{~min}$ intervals as required. The administration of liquid during CPR was limited to $<2 \mathrm{ml}$. Defibrillation was performed with direct-current single-phase (defibrillation energy, $5 \mathrm{~J}$ ) if the electrocardiogram displayed ventricular fibrillation at $1 \mathrm{~min}$ after CPR. If the defibrillation failed, CPR was repeated and defibrillations were repeated at 1 min after CPR. Spontaneous circulation was restored (18) if supraventricular cardiac rhythm was restored; the average arterial pressure was $>60 \mathrm{mmHg}$ and was maintained for $\geq 10 \mathrm{~min}$. If the spontaneous circulation of the rats was not restored after 10 min with the above treatment, CPR was considered to have failed.

Treatments following resuscitation. Rats that exhibited successful restoration of spontaneous circulation (ROSC) were monitored using an electrocardiogram and for hemodynamics for $4 \mathrm{~h}$. During this period, rats with weak autonomous respirations were mechanically ventilated. The respiratory condition of each rat was evaluated every $15 \mathrm{~min}$ to determine whether further mechanical ventilation was required. Mechanical ventilation was stopped at $4 \mathrm{~h}$, after all tubes were removed and wounds were sutured. Each rat was fed in a separate cage. All animal experiments were conducted on a thermostatic table (Suzhou Liying Experimental Co., Ltd., Suzhou, China), which maintained the rat body temperature at $37.5 \pm 0.2^{\circ} \mathrm{C}$. A heat lamp (Suzhou Liying Experimental Co., Ltd.) was additionally used for rats with a body temperature of $<36.5^{\circ} \mathrm{C}$. Immediately following ROSC, NaHS $(14 \mu \mathrm{mol} / \mathrm{kg} / \mathrm{day}$, diluted in $1.5 \mathrm{ml}$ normal saline; Sigma-Aldrich Trading Co. Ltd, Shanghai, China) was injected into the rats via the femoral 
vein and then every subsequent $8 \mathrm{~h}$ intraperitoneally (three equal $0.5-\mathrm{ml}$ doses/day) in the NaHS group. Hydroxylamine solution $(40 \mu \mathrm{mol} / \mathrm{kg} / \mathrm{day}$, diluted in $1.5 \mathrm{ml}$ normal saline; Sigma-Aldrich Trading Co. Ltd) was administered to the rats in the hydroxylamine group in the same manner as that used for NaHS. The control group received routine CPR, and an equal quantity of saline as a control in the same manner as that used the first two groups. The end point of observation was 7 days. Animals with failed CA induction, or animals that died prior to the end point of observation, were excluded from the final data analysis.

Neurological deficit scoring (NDS). NDS was performed prior to CA and at 4, 12, 24, 72 and $168 \mathrm{~h}$ after CPR, as previously described (19).

Sample collection. After NDS at each specified experimental time point (prior to $\mathrm{CA}$ and 4, 12, 24, 72 and $168 \mathrm{~h}$ after), $2 \mathrm{ml}$ blood was obtained from the femoral vein. A 1-ml volume of this blood sample was sealed in an EP tube containing coagulant and deproteinization reagent for $\mathrm{H}_{2} \mathrm{~S}$ measurement. The remaining $1 \mathrm{ml}$ blood was collected for the examination of neuron-specific enolase (NSE) and S100 $\beta$. Samples were centrifuged at $2,504 \mathrm{x} \mathrm{g}$ for $15 \mathrm{~min}$ at $4^{\circ} \mathrm{C}$, within $30 \mathrm{~min}$ of collection. The sealed EP tube with serum was numbered and stored at $-80^{\circ} \mathrm{C}$. An equal volume of blood from donor mice was transfused immediately into the experimental mice following blood collection, in order to avoid unstable blood circulation and its influence on the experiment results. Serum levels of $\mathrm{H}_{2} \mathrm{~S}$ were measured using the deproteinization method (20) and the levels of NSE and S100 $\beta$ were measured using ELISA kits (R\&D Systems, Inc., Minneapolis, MN, USA).

Morris water maze, beam walking and prehensile traction tests. As described in previous studies $(21,22)$, the Morris water maze test consisted of a hidden platform test, probe test and visible platform test. Animals were subjected to the Morris water maze test individually 1 day prior to CA and 3, 5 and 7 days after CPR. The hidden platform test was performed in duplicate, once in the morning and once in the afternoon, with the average number as the result for each day of testing. The water maze apparatus (Zhenghua Biotech Co., Ltd., Hebei, China) consisted of a circular glass pool of $150 \mathrm{~cm}$ diameter and a movable glass platform $12 \mathrm{~cm}$ in diameter and $35 \mathrm{~cm}$ in height. A video camera was positioned on a platform that was $210 \mathrm{~cm}$ above the bottom of the pool. The wall of the maze was painted black and the water was dyed black using ink. The pool was filled with water to the $36-\mathrm{cm}$ mark and maintained at $24 \pm 1^{\circ} \mathrm{C}$. The pool was divided arbitrarily into four equally sized quadrants. The platform was submerged in the middle of zone I such that its surface was $1 \mathrm{~cm}$ below the water surface and $20 \mathrm{~cm}$ away from the wall of the maze. The hidden platform test measured rat behavioral change by quantifying escape latency and swimming distance. The probe test was conducted 7 days after CPR, subsequent to the hidden platform test. After removing the platform, the animals were left to swim for $120 \mathrm{sec}$. During this period, the number of instances the animal passed each quadrant, as well as the swimming was recorded by a video tracking system. In the visible platform test, which was performed after the probe test, escape latency and swimming distance were recorded.

The beam walking test (BWT) and the prehensile traction test were conducted 1 day prior to CA and 3,5 and 7 days after CPR, following established methods $(23,24)$.

Preparation of samples for apoptosis analyses. Following the endpoint of the neural behavioral tests, the animals in each group were divided at random into two subgroups for the analysis of apoptosis by either immunohistological examination by TUNEL assay, or by western blot analysis. The brains of rats that were to undergo immunohistochemical (IHC) examination were fixed via transcardial perfusion of the rats with 4\% paraformaldehyde for 20-30 min prior to decapitation and removal of the brain. Brain tissue was then fixed in $4 \%$ paraformaldehyde. Sections of brain tissue 3-4 $\mathrm{mm}$ in size were excised between the optic chiasm and optic nerve, embedded in paraffin and sectioned for IHC examination. Hippocampal volume was measured by stereological analysis after hematoxylin and eosin staining (25). Rats that were to undergo western blot analysis were sacrificed by cervical dislocation. The brains were removed immediately, and the hippocampal region was isolated and rapidly frozen using liquid nitrogen. Samples were stored at $-80^{\circ} \mathrm{C}$ prior to detection of cysteine-containing aspartate-specific protease- 3 (caspase-3) and B-cell leukemia/lymphoma 2 (Bcl-2) protein expression levels.

TUNEL assay for apoptosis analysis. Apoptosis assays were performed using a TUNEL assay (TUNEL Cell Apoptosis Detection kit; Nanjing KeyGen Biotech, Co., Ltd., Nanjing, China). Cells exhibiting characteristics of apoptosis, combined with brown nuclear staining, were considered to be positive for apoptosis. Expression of caspase-3 and Bcl-2 in the hippocampal CA1 region was examined using streptavidin biotin peroxidase complex immunohistochemical staining kits (Wuhan Boster Bio-Engineering Ltd. Co., Wuhan, China). Cells displaying dark brown staining were considered to be positive.

Western blot for apoptosis analysis. The expression levels of caspase-3 and Bcl-2 in the hippocampal CA1 region were additionally examined using western blot analysis, according to a previously reported method (26). The primary antibodies included polyclonal rabbit anti-active caspase-3 antibody (1:1,000; \#9664; Cell Signaling Technology, Inc., Danvers, MA, USA) and polyclonal rabbit anti-Bcl-2 antibody (1:50; ab7973; Abcam, Inc., Cambridge, MA, USA). The secondary antibody was goat-anti-rabbit IgG (1:5,000; SC-2004; Santa Cruz Biotechnology, Inc., Santa Cruz, CA, USA) for $2 \mathrm{~h}$. Semi-quantitative image analysis was performed using Image Pro Plus 6.0 software (Media Cybernetics, Inc., Rockville, MD, USA). Five optical microscope fields (DVM6; Leica Microsystems GmbH, Berlin, Germany) were selected at random from the same region of each tissue section and the apoptotic index (AI) was calculated as a percentage of total apoptotic cells. For caspase-3 and Bcl-2 expression, integrated optical density (IOD) was determined for each field. Average IOD from the five fields was calculated as the mean IOD for the region. Western blot analysis results were analyzed following 

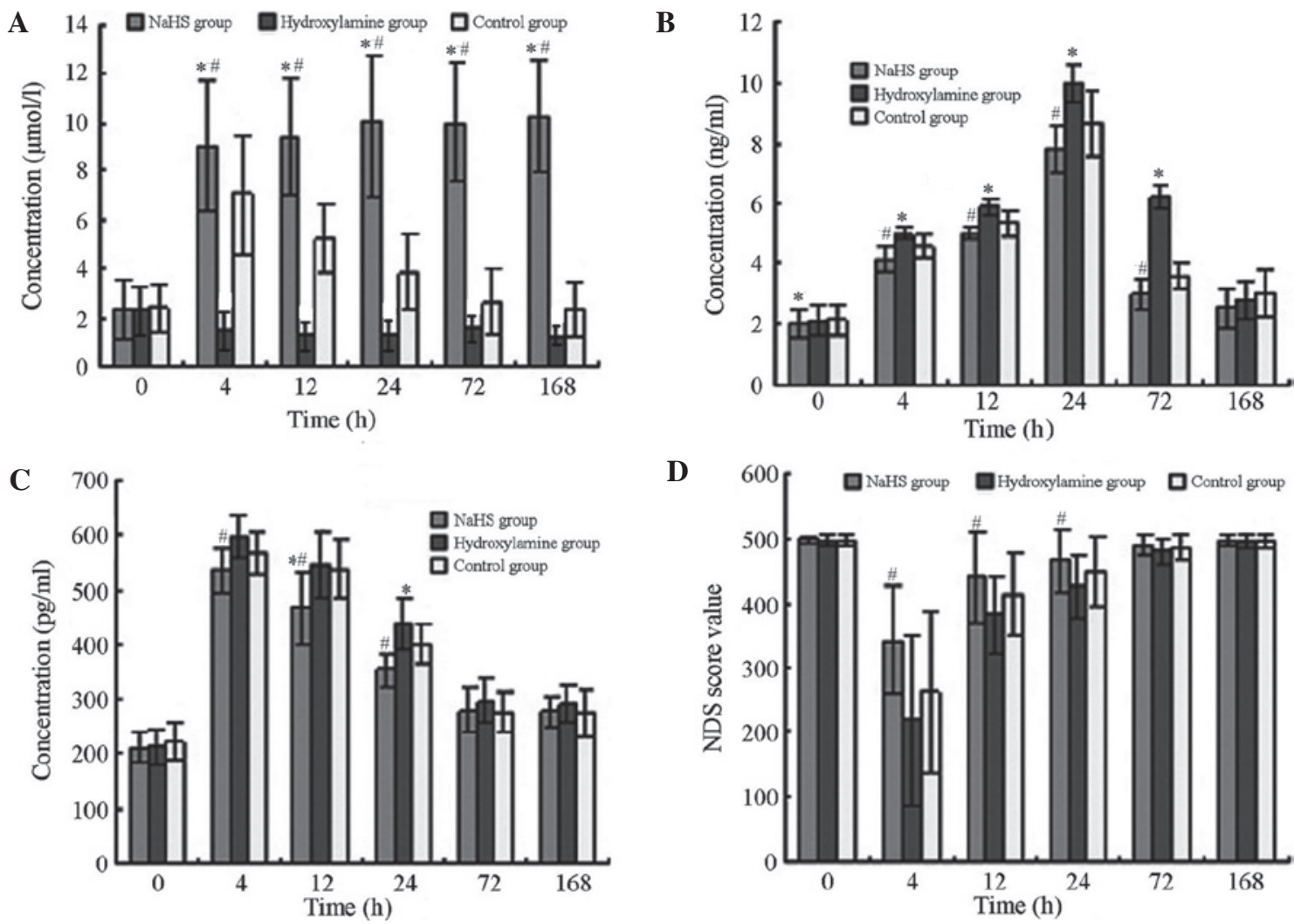

Figure 1. Comparison of serum concentrations of (A) $\mathrm{H}_{2} \mathrm{~S}$, (B) NSE, (C) S100 $\beta$ and (D) NDS at different time points before and after CPR. "P<0.05 vs. control group; ${ }^{~} \mathrm{P}<0.05$ vs. hydroxylamine group. NaHS, sodium hydrosulfide; $\mathrm{H}_{2} \mathrm{~S}$, hydrogen sulfide; NSE, neuron-specific enolase; NDS, neurological deficit scoring; $\mathrm{CPR}$, cardiopulmonary resuscitation; $\mathrm{CA}$, cardiac arrest.

scanning of the blots. Quantity One image processing software (Bio-Rad Laboratories, Inc., Hercules, CA, USA) was used to semi-quantitatively calculate the luminance ratio of each protein band.

Statistical analysis. Statistical analyses were performed using SPSS software, version 13.0 (SPSS, Inc., Chicago, IL, USA). Categorical data were organized into contingency tables. Quantitative data are expressed as the mean \pm standard deviation. Pair-wise comparisons between groups were performed using the Student-Newman-Keuls method. $\mathrm{P}<0.05$ was considered to indicate a statistically significant difference.

\section{Results}

$C A$ model. In the NaHS group, the establishment of the CA model was attempted in 31 Sprague-Dawley rats with a success rate of $93.5 \%$ (29/31) and an ROSC rate of $93.1 \%$ (27/29). Seven rats died after ROSC prior to the end point of observation $(7 / 27,25.9 \%)$. In the hydroxylamine group, establishment of the CA model was attempted in 35 rats with a success rate of $91.4 \%(32 / 35)$ and an ROSC rate of $93.8 \%$ (30/32). A total of 10 rats died after ROSC prior to the end point of observation, resulting in a mortality rate of $33.3 \%$ (10/30). In the control group, CA was successfully induced in a total of 32 rats $(97.0 \%, 32 / 33)$. The ROSC rate was $90.6 \%$ (29/32) and 9 rats died after ROSC but prior to the end point of observation, resulting in a mortality rate of $31.0 \%(9 / 29)$. No significant differences were observed in the rates of successful
CA model induction, ROSC and mortality following ROSC among the three groups $(\mathrm{P}>0.05)$.

Comparison of serum $\mathrm{H}_{2} \mathrm{~S}, \mathrm{NSE}$ and S100 $\beta$ concentrations and NDS after CPR. As presented in Fig. 1, the differences in serum $\mathrm{H}_{2} \mathrm{~S}$, NSE and $\mathrm{S} 100 \beta$ concentrations and NDS before and after CPR were statistically significant ( $\mathrm{F}=223.496$, 111.667, 30.194 and 7.318; $\mathrm{P}<0.001,<0.001,<0.001$ and 0.001 , respectively). In the control group, the $\mathrm{H}_{2} \mathrm{~S}$ concentration gradually increased following CA, peaking at $4 \mathrm{~h}$ after CPR, then reduced over time. The $\mathrm{H}_{2} \mathrm{~S}$ concentration in the NaHS group increased after CPR while the $\mathrm{H}_{2} \mathrm{~S}$ concentration in the hydroxylamine group reduced after CPR. Significant differences were detected in $\mathrm{H}_{2} \mathrm{~S}$ levels among the three groups at each time point $(\mathrm{P}<0.05)$. Serum concentrations of NSE and $\mathrm{S} 100 \beta$ in all animals gradually increased and peaked respectively at 24 and $4 \mathrm{~h}$, respectively, after CPR prior to declining. The peak values of the two parameters were lowest in the NaHS group and highest in the hydroxylamine group. NSE and $\mathrm{S} 100 \beta$ concentrations in the NaHS group were significantly reduced compared with those in the hydroxylamine group at 4, 12, 24 and $72 \mathrm{~h}$ after $\mathrm{CA} / \mathrm{CPR}(\mathrm{P}<0.05)$, but not at 168 h. Following CA/CPR, NDS values reduced significantly, with the lowest values observed at $4 \mathrm{~h}$, followed by a trend of gradual increase. The range of NDS decline was the lowest in the NaHS group and was largest in the hydroxylamine group following CPR. NDS values from the NaHS group were significantly higher compared with those in the hydroxylamine group at 4, 12 and $24 \mathrm{~h}$ after $\mathrm{CA} / \mathrm{CPR}(\mathrm{P}<0.05)$. 

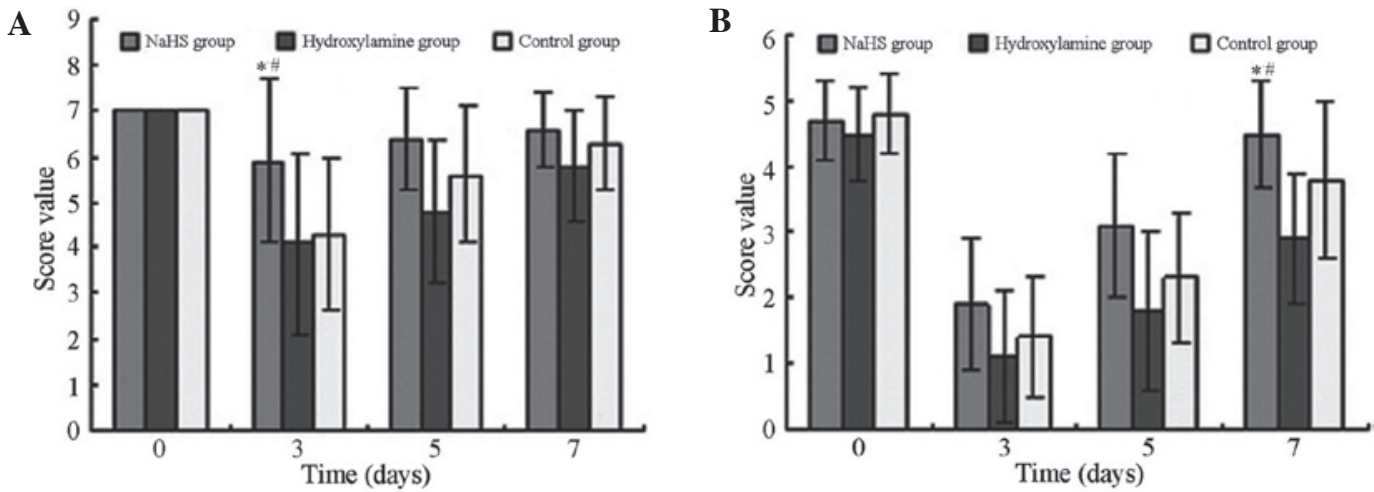

Figure 2. Comparison of scores from the (A) beam walking and (B) prehensile traction tests. ${ }^{*} \mathrm{P}<0.05$ vs. control group; ${ }^{*} \mathrm{P}<0.05$ vs. hydroxylamine group. NaHS, sodium hydrosulfide.

A

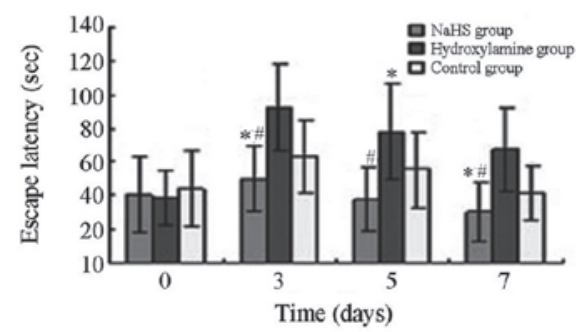

C

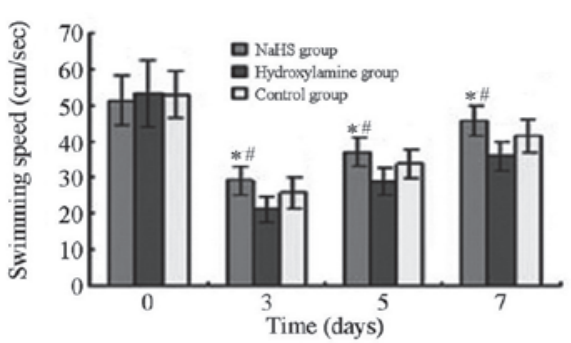

$\mathbf{E}$

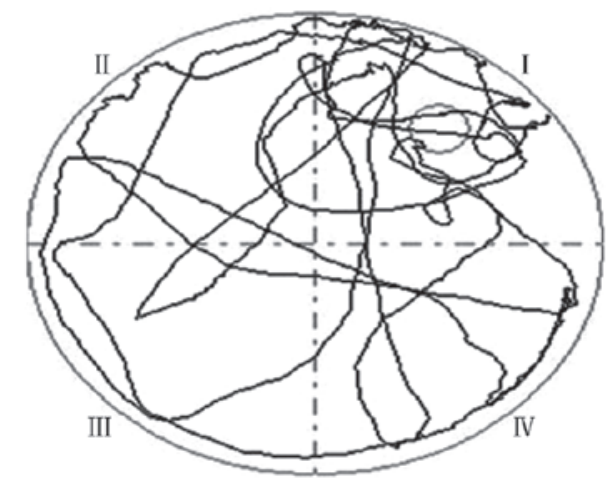

B

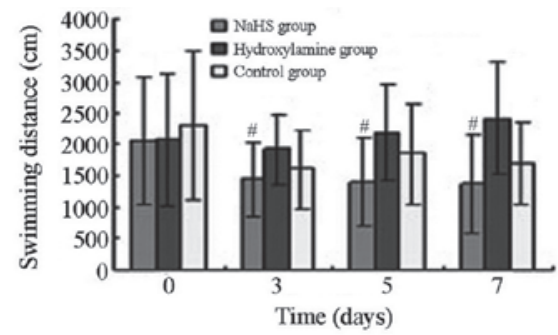

D

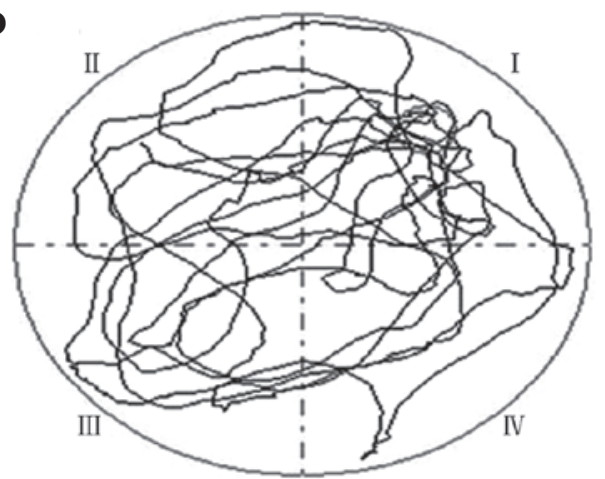

$\mathbf{F}$

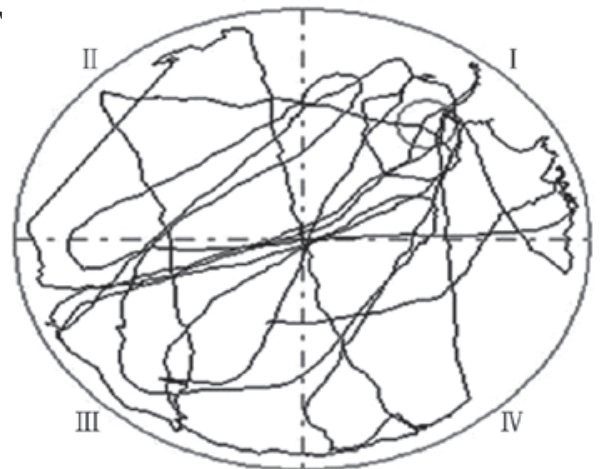

Figure 3. Morris water maze results comparison. (A) Escape latency, (B) swimming distance and (C) swimming speed in the hidden platform test. Swim paths of representative rats from the (D) NaHS, (E) hydroxylamine and (F) control groups in the probe test. ${ }^{*} \mathrm{P}<0.05$ vs. control group; ${ }^{\text {}} \mathrm{P}<0.05$ vs. hydroxylamine group. At any time point after CPR, the NaHS group had the shortest escape latency and swimming distance, and the quickest swimming speed, whereas the hydroxylamine group had the longest escape latency and swimming distance, and the slowest swimming speed. NaHS, sodium hydrosulfide; CPR, cardiopulmonary resuscitation.

BWT and the prehensile traction test. As presented in Fig. 2 the scores of the beam walking and prehensile traction tests suggest significant differences among the three groups $(\mathrm{F}=5.503$ and 3.246; $\mathrm{P}=0.007$ and 0.046 , respectively). After
$\mathrm{CA} / \mathrm{CPR}$, the scores in all groups declined and reached the lowest value at 3 days. Among the three groups, scores in the hydroxylamine group exhibited the most marked decline at 3 days; however, the scores subsequently recovered. At all 
Table I. Comparison of results from the Morris water maze probe test and visible platform test after cardiopulmonary resuscitation (mean \pm standard deviation).

\begin{tabular}{lccccc}
\hline & \multicolumn{2}{c}{ Probe test } & & \multicolumn{2}{c}{ Visible platform test } \\
\cline { 2 - 3 } Groups & Distance $(\mathrm{cm})$ & Platform passing $(\mathrm{n})$ & & Escape latency $(\mathrm{sec})$ & Swimming speed $(\mathrm{cm} / \mathrm{sec})$ \\
\hline NaHS & $5,329.6 \pm 540.0^{\mathrm{a}, \mathrm{b}}$ & $7.6 \pm 2.0^{\mathrm{a}, \mathrm{b}}$ & & $5.8 \pm 2.3$ & $44.7 \pm 4.3^{\mathrm{a}, \mathrm{b}}$ \\
Hydroxylamine & $4,070.4 \pm 500.9$ & $3.4 \pm 1.9$ & & $6.4 \pm 2.5$ & $36.4 \pm 3.9$ \\
Control & $4,835.8 \pm 700.7$ & $5.1 \pm 2.2$ & & $5.3 \pm 2.4$ & $40.9 \pm 5.1$ \\
\hline
\end{tabular}

${ }^{\mathrm{a}} \mathrm{P}<0.05$ vs. control group; ${ }^{\mathrm{b}}<0.05$ vs. hydroxylamine group. NaHS, sodium hydrosulfide.

A

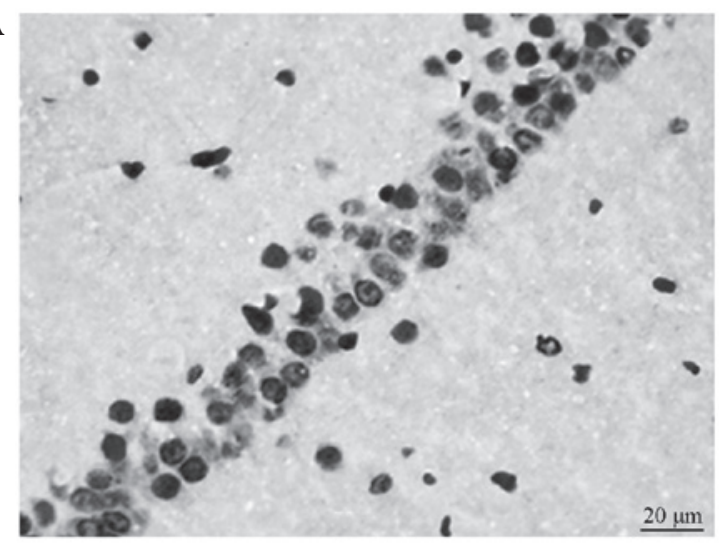

C

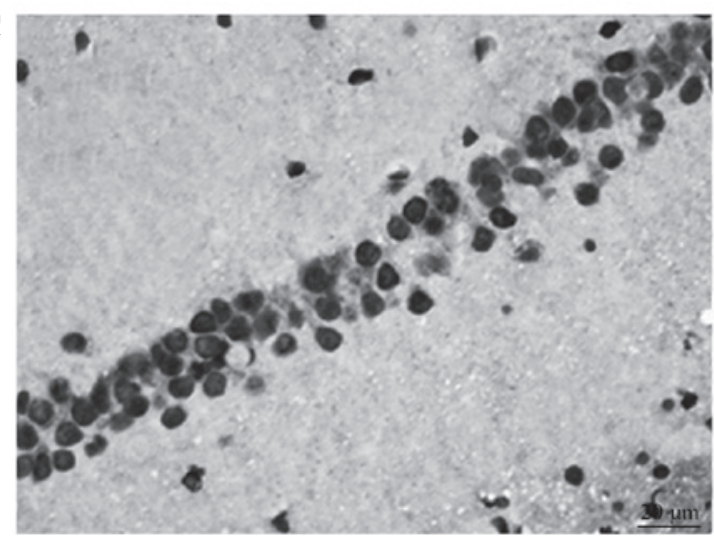

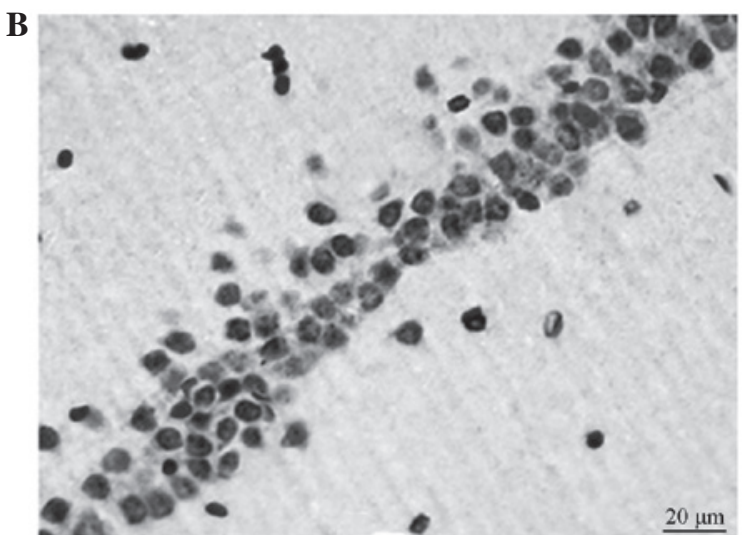

D

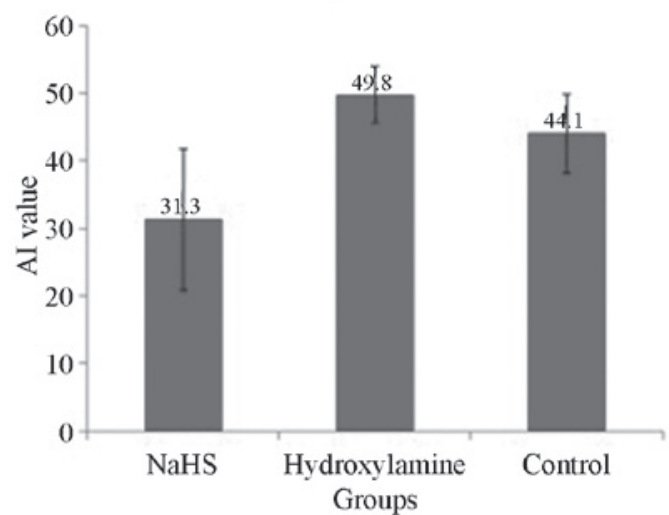

Figure 4. Comparison of apoptotic analysis in the rat hippocampal CA1 region at 7 days after cardiopulmonary resuscitation (CPR; TUNEL assay; magnification, $\mathrm{x} 400$ ). Representative images from the (A) NaHS, (B) hydroxylamine and (C) control groups. (D) Significant difference in the AI of neurons in the rat hippocampal CA1 region was observed among the three experimental groups ( $\mathrm{F}=8.269, \mathrm{P}=0.002)$. NaHS, sodium hydrosulfide; AI, apoptotic index.

time points after CPR conduction, the NaHS group exhibited the highest score, whereas the hydroxylamine group presented significantly reduced scores $(\mathrm{P}<0.05)$.

Morris water maze test. As displayed in Fig. 3, in the hidden platform test, there were significant differences in escape latency, swimming distance and speed among the three groups $(\mathrm{F}=12.289,3.712$ and 17.441; $\mathrm{P}=0.000,0.031$ and $<0.001$, respectively). At all time points after CPR, the NaHS group exhibited the shortest escape latency and swimming distance, and highest swimming speed, whereas the hydroxylamine group displayed the longest escape latency and swimming distance, and lowest swimming speed. As shown in Table I, in the probe test, the swimming distance and number of pass- ings of the platform differed significantly among the groups $(\mathrm{P}<0.05)$. The NaHS group exhibited the longest swimming distance and the highest number of passings of the platform, whereas the hydroxylamine group had the shortest swimming distance and the least number of passings of the platform. In the visible platform test, no significant differences were observed in escape latency among the three groups $(\mathrm{F}=1.131$, $\mathrm{P}=0.330$ ).

Apoptosis of neurons in the hippocampal region. All rats that underwent CA presented with numerous TUNEL-positive pyramidal neurons in the CA1 region of the hippocampus at 7 days after CPR. Significantly reduced numbers of TUNEL positive neurons were observed in the NaHS group compared 

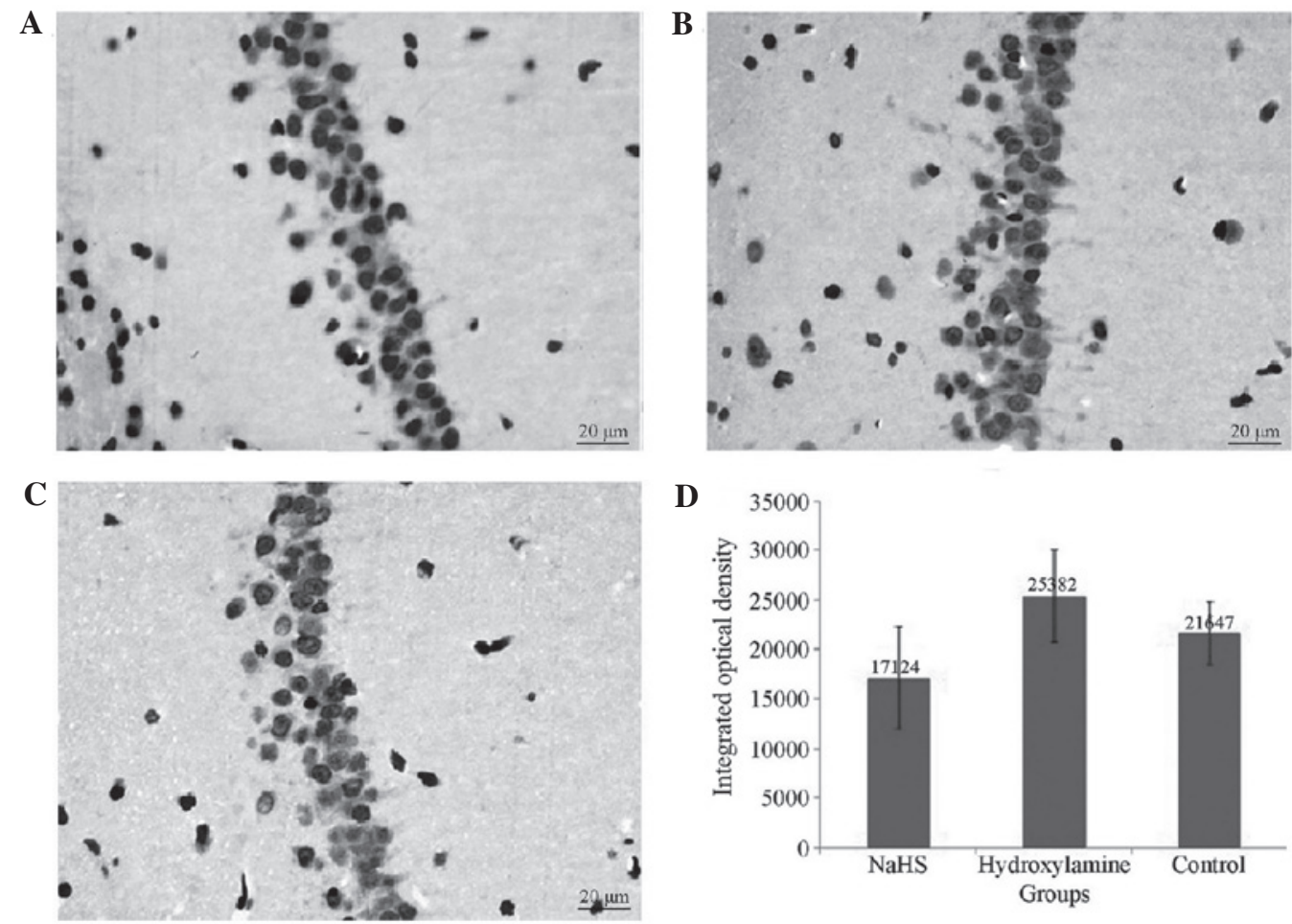

Figure 5. Comparison of caspase-3 expression by immunohistochemical analysis in the rat CA1 region at 7 days after CPR (streptoavidin biotinperoxidase complex; magnification, x400). Images from the (A) NaHS group, (B) hydroxylamine group and (C) control group. (D) Comparison of the integrated optical density of caspase-3 expression in the rat hippocampal CA1 region among the three experimental groups ( $\mathrm{F}=8.774$, $\mathrm{P}=0.001)$. NaHS, sodium hydrosulfide; CPR, cardiopulmonary resuscitation.

A
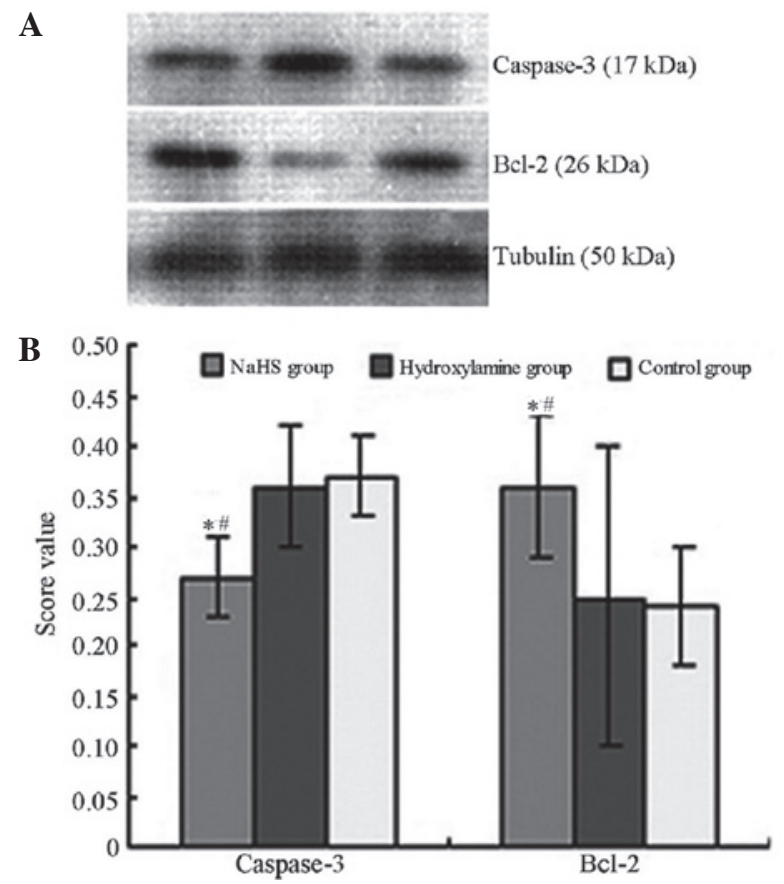

Figure 6. Western blot analysis of hippocampal caspase-3 and Bcl-2 protein expression among groups. (A) Western blot images. (B) Semi-quantitative comparison of caspase-3/tubulin and $\mathrm{Bcl}-2 / \mathrm{T}=$ tubulin luminance ratio among groups $\left(\mathrm{F}=12.514\right.$ and $4.411 ; \mathrm{P}=0.000$ and 0.022 , respectively). ${ }^{*} \mathrm{P}<0.05$ vs. control group; ${ }^{\mathrm{P}} \mathrm{P}<0.05$ vs. hydroxylamine group. NaHS, sodium hydrosulfide.

with the hydroxylamine group (Fig. 4). Concomitantly, significantly reduced caspase-3 expression levels (Figs. 5 and 6) and increased Bcl-2 (Figs. 6 and 7) expression levels were observed in the NaHS group compared with the hydroxylamine and control groups. No significant differences were detected in the expression levels of caspase- 3 and $\mathrm{Bcl}-2$ between the hydroxylamine and control groups.

Stereological analysis of the hippocampus. Stereological analyses detected no significant differences in the volume of the hippocampus among the groups at 7 days after CPR (P>0.05; Fig. 8).

\section{Discussion}

The results of the present study indicate that the serum $\mathrm{H}_{2} \mathrm{~S}$ concentration in rats of the NaHS group after CPR was significantly elevated, whereas the serum $\mathrm{H}_{2} \mathrm{~S}$ concentration in rats treated with hydroxylamine was reduced, suggesting that exogenous treatments are able to alter $\mathrm{H}_{2} \mathrm{~S}$ levels in vivo. Furthermore, NaHS treatment attenuates neuronal injury and improves neural functional performance, whereas hydroxylamine exaggerates neuronal injury and exacerbates learning and memory problems. NaHS treatment markedly increases Bcl-2 expression levels and reduces caspase- 3 expression. The present results suggest that $\mathrm{H}_{2} \mathrm{~S}$ may possess potential therapeutic value for brain injury following $\mathrm{CA}$.

NSE is a specific enzyme located primarily in brain neurons and neuroendocrine cells, and is involved in glycolysis. Following CA/CPR, NSE may be released from ischemically injured neurons and traverse the blood brain barrier into the circulation; therefore, serum NSE levels reflect the severity of brain damage after CA and indicate disease outcome $(27,28)$. 

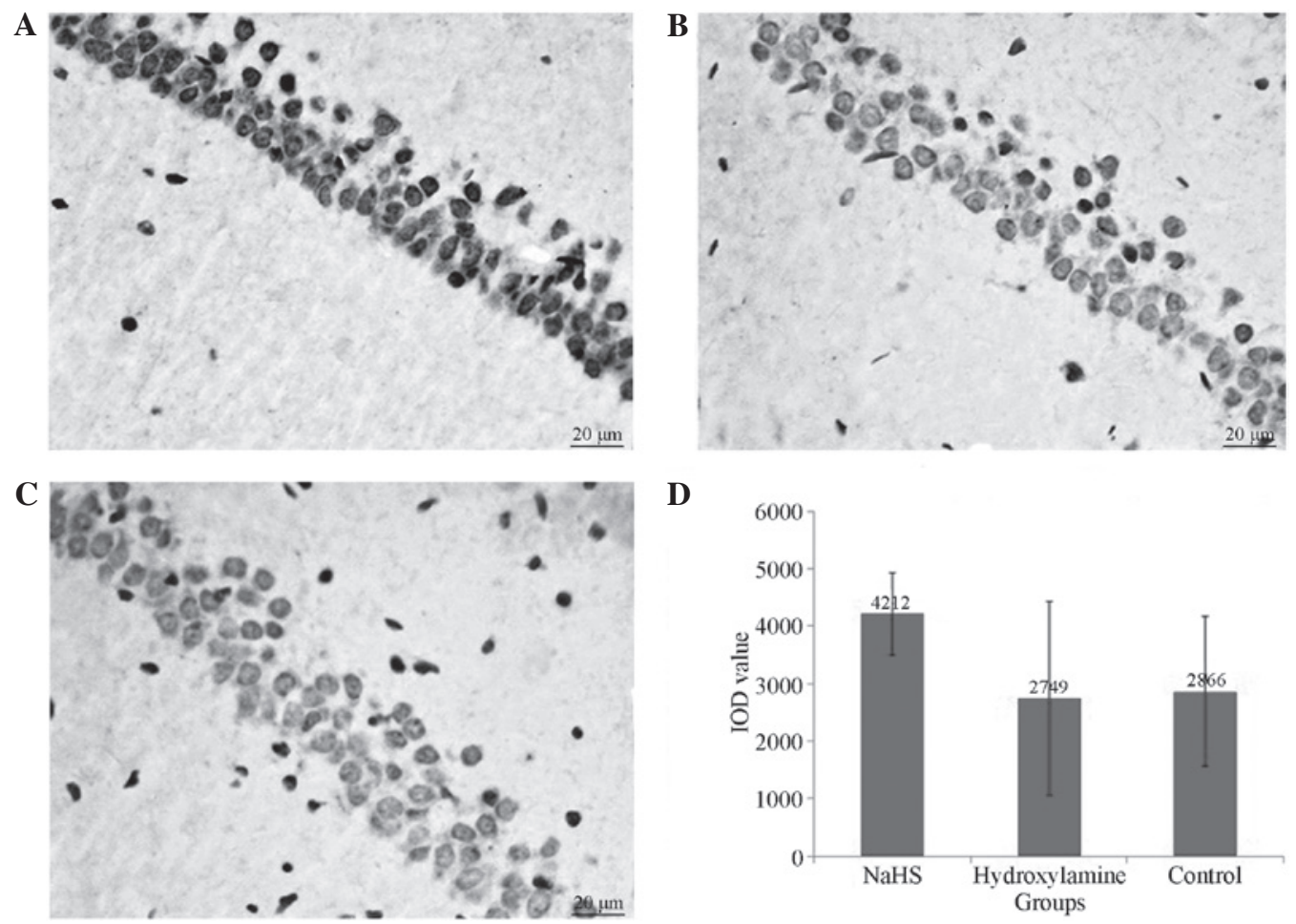

Figure 7. Comparison of Bcl-2 expression by immunohistochemical analysis in the rat $\mathrm{CA} 1$ region at 7 days after $\mathrm{CPR}$ (streptavidin biotin peroxidase complex; magnification, x400). Representative mages from the (A) NaHS, (B) hydroxylamine and (C) control groups. (D) Comparison of integrated optical density (IOD) of Bcl-2 expression in hippocampal CA1 region of rats among the three experimental groups $(\mathrm{F}=6.858, \mathrm{P}=0.016)$. Different lowercase letters indicate statistically significant difference $(\mathrm{P}<0.05)$. NaHS, sodium hydrosulfide; $\mathrm{CPR}$, cardiopulmonary resuscitation.

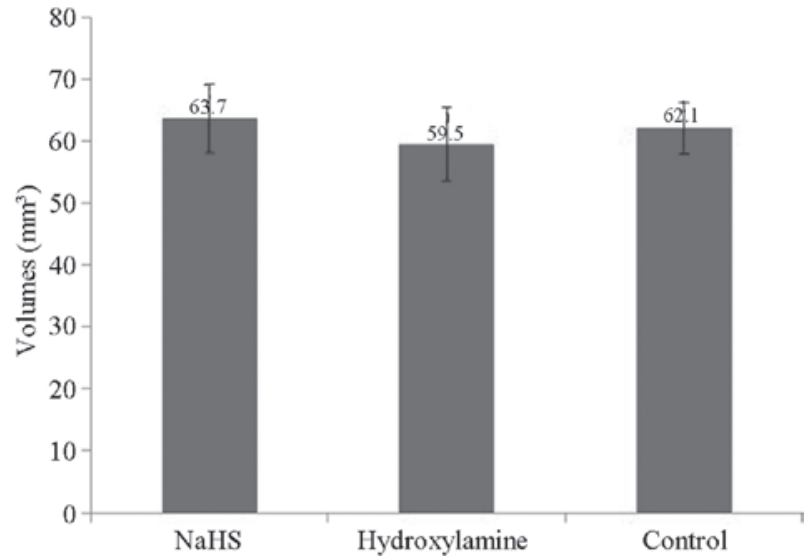

Figure 8. Comparison of hippocampal volume in the three groups $(\mathrm{F}=1.627$, $\mathrm{P}=0.215)$. NaHS, sodium hydrosulfide.

The calcium binding protein $\mathrm{S} 100 \beta$ is an axonal growth factor that is predominantly produced and secreted by glial cells, and is widely expressed in nervous tissue. Serum S100 $\beta$ levels are used as biomarkers for disease progression after CA/CPR and neurological prognosis (29) due to their regularity of alteration and marked correlation with the severity of the injury (30). In the present study, the serum concentrations of NSE and S100 $\beta$ gradually increased and peaked at 24 or $4 \mathrm{~h}$, respectively, after $\mathrm{CA} / \mathrm{CPR}$. In addition, serum NSE and S100 $\beta$ concentrations reduced or increased according to the $\mathrm{H}_{2} \mathrm{~S}$ levels in serum, suggesting that $\mathrm{H}_{2} \mathrm{~S}$ therapy may be able to reduce rat brain damage following CA to certain extent. Compared with NSE and S100 $\beta$, NDS is able to more directly indicate the extent of cerebral function damage after CPR, and to determine the effectiveness of treatment $(19,31,32)$. Therefore, NDS was also evaluated in the present study. The NDS score reduced significantly in rats following CA/CPR. However, the NDS score of NaHS-treated rats was higher that that of rats treated with hydroxylamine at $24 \mathrm{~h}$ after $\mathrm{CPR}$, indicating a protective effect against brain damage after $\mathrm{CA}$.

Neural behavior is a crucial function of the body, which controls and coordinates the body's normal activities, in addition to being influenced and regulated by the state of other organ systems. Following CPR, the body may not display clear signs and symptoms of the neurological state, but patients may present with abnormal memory, sensory, motor and cognitive functions. Therefore, neurobehavioral examination is frequently a key index for evaluating brain functional status and prognosis after CPR (33-35). The Morris water maze experiment is a classical neurobehavioral test, which includes a hidden platform test, space exploration test and visible platform test. The Morris water maze is designed to allow animals to learn to search for a hidden platform under water, and by analyzing the time and path taken to search for the platform, animal memory function may be assessed. The Morris water maze allows the effective detection of rat spatial learning and memory abilities, which involves the medial temporal lobe limbic region including the hippocampus (36). In the present study, the spatial learning and memory ability of the rats reduced following CA, but subsequently recovered to a certain extent. In the hidden platform test, the escape latency of the NaHS group was lower than that of the control group at every time point after CPR; however, in the hydroxylamine group the escape latency and swimming distance increased after CPR. In 
the space exploration experiments, the NaHS group displayed a significant increase in the number of passings of the platform, while the hydroxylamine group exhibited a significant reduction. This indicated that improving body levels of $\mathrm{H}_{2} \mathrm{~S}$ led to improved rat spatial learning and memory ability after $\mathrm{CPR}$, and reducing $\mathrm{H}_{2} \mathrm{~S}$ levels may result in delayed recovery of spatial learning and memorizing abilities.

The BWT is used to detect whether the established operant conditioning reflex is impaired after injury in rats. The BWT is frequently used to assess whether there are impairments in the functions of dynamic balance, motor coordination, learning and memorizing abilities $(37,38)$. The prehensile traction test is an index for evaluating rat forepaw gripping power, muscle strength, balance and motor function $(24,39,40)$. In the present study, the scores for the beam walking and prehensile traction testing reduced significantly in the rats after $\mathrm{CA}$, and increased gradually over the 7 days after CPR. A comparison of the results in these three groups showed that the performances of the NaHS-treated rats were the most improved, while the hydroxylamine group displayed the worst performance. This indicated that increasing $\mathrm{H}_{2} \mathrm{~S}$ levels improved the balance, coordination and muscle strength of rats after CPR, and reducing $\mathrm{H}_{2} \mathrm{~S}$ levels delayed the recovery of motor ability.

The results of the neural behavior and function analysis are consistent with previous studies, in which Knapp et al reported that the administration of $\mathrm{Na}_{2} \mathrm{~S}$ reduces sensorimotor deficits $72 \mathrm{~h}$ after CA/CPR in rats (15) and Kida et al found that $\mathrm{Na}_{2} \mathrm{~S}$ improves neurological function at $96 \mathrm{~h}$ after CA and CPR (13). In contrast to previous studies involving rodents, Derwall et al observed in a porcine model that high-dose $\mathrm{Na}_{2} \mathrm{~S}(1 \mathrm{mg} / \mathrm{kg})$ bolus followed by infusion at $1 \mathrm{mg} / \mathrm{kg}^{\prime} \mathrm{h}$ for $2 \mathrm{~h}$ did not improve neurological outcomes (14). This may be attributable to the hypothesis that a lower concentration of $\mathrm{H}_{2} \mathrm{~S}$ exerts a protective effect on cells while higher levels of $\mathrm{H}_{2} \mathrm{~S}$ exposure lead to cytotoxicity (41). In the present study, $14 \mu \mathrm{mol} / \mathrm{kg} /$ day NaHS was intraperitoneally administered, and it has previously been confirmed that the protective effect against neuronal injury conferred by NaHS is dose-dependent (42). In addition to its function as an inhibitor of CBS, hydroxylamine can be metabolized to NO (43), which may be neurotoxic and contributes to neuronal damage (44).

In the present study, levels of neuronal apoptosis in the hippocampus were assessed at 7 days after CPR, and it was observed that in response to the elevated levels of serum $\mathrm{H}_{2} \mathrm{~S}$ in the NaHS group, the apoptotic index of pyramidal neurons in the hippocampal CA1 region and the expression level of the pro-apoptotic protein caspase-3 appeared to reduce, while the expression of the anti-apoptotic protein $\mathrm{Bcl}-2$ increased. By contrast, in response to the reduced levels of serum $\mathrm{H}_{2} \mathrm{~S}$ in the hydroxylamine group, the apoptosis index of pyramidal neurons and caspase- 3 expression levels in the CA1 region increased, whereas Bcl-2 expression levels decreased. This result suggests that increased endogenous $\mathrm{H}_{2} \mathrm{~S}$ levels may inhibit neuronal apoptosis, whereas inhibiting endogenous $\mathrm{H}_{2} \mathrm{~S}$ production may promote apoptosis. However, this is contradictory to the study by Knapp et al, in which the administration of $\mathrm{Na}_{2} \mathrm{~S}$ failed to significantly reduce the number of TUNEL-positive cells and caspase activity in the CA1 region of the hippocampus 7 days after CPR (15). This may be attributable to the difference in potentials of the $\mathrm{H}_{2} \mathrm{~S}$ donors that were used and the short infusion time $(0.5 \mathrm{mg} / \mathrm{kg}, 1 \mathrm{~min}$ prior to the initiation of CPR, followed by a continuous infusion of $\mathrm{Na}_{2} \mathrm{~S}$ for $6 \mathrm{~h}, 1 \mathrm{mg} / \mathrm{kg} / \mathrm{h}$ ) in the previous study.

In conclusion, the in vivo modulation of $\mathrm{H}_{2} \mathrm{~S}$ levels may influence the occurrence and development of brain damage in rats following CA. After ROSC, elevating the $\mathrm{H}_{2} \mathrm{~S}$ levels via a therapeutic intervention may improve neural function damage in rats that have undergone $\mathrm{CPR}$.

The present study has certain limitations. i) It was observed that certain doses of NaHS appeared to reduce the biochemical markers of nerve injury, improve nervous function defect score, improve neurobehavioral symptoms and reduce neuronal apoptosis in hippocampal tissue. However, these indices in the hydroxylamine group exhibited adverse changes to various degrees. No significant differences were observed between the hydroxylamine and saline control groups when multiple level comparisons were performed. ii) Theoretically, as cellular apoptosis increases, hippocampal volume is expected to exhibit a certain degree of atrophy; however, no differences in hippocampal volume were observed among the groups in the current study. iii) There were no obvious increases in mortality rate following ROSC, which is the primary index for evaluating the effectiveness of CPR. As for the reason for this, as only a single dose level was used in this experiment, it is hypothesized that there may be an optimal effective dose range of $\mathrm{H}_{2} \mathrm{~S}$. iv) Body temperature, heart rate, respiratory rate and blood pressure were measured during the experiment. However, all animals were placed on a thermostatic table $4 \mathrm{~h}$ after ROSC and the body temperature was maintained at $37.5 \pm 0.2^{\circ} \mathrm{C}$. From $5 \mathrm{~h}$ after ROSC to the end point of observation, a heat lamp was additionally used for the rats with poor status and a body temperature $<36.5^{\circ} \mathrm{C}$. Heart rate and the respiratory rate are directly associated with body temperature. Furthermore, adrenalin affects heart rate and blood pressure in the early stages following ROSC. Blood pressure measurements may differ significantly between these two methods. In addition, mechanical ventilation may effect the respiratory rate. Thus, although the physiological indices were maintained as consistently as possible during the experiment, the above factors were not excluded. Thus, the systemic detection and comparison of certain physiological indices were not performed. The differences between these indices may have affected the analysis of the experimental results. v) The scale of the present study was relatively small, which may have resulted in experimental bias.

\section{Acknowledgements}

The present study was supported by grants from Medical innovation project of Fujian Province, China (no. 2011-CXB-31) and the social development research project of Xiamen, China (no. 3502Z20114006, 3502Z20124042 and 3502Z20134003). The funding source had no role in the study design, the collection and interpretation of the data, writing of the report, or decision to submit the paper for publication. The authors would like to thank the staff of the Emergency Department of the First Affiliated Hospital of Xiamen University and the Key Laboratory on Assisted Circulation of Ministry of Health of Sun Yat-Sen University for their excellent technical assistance and constructive criticism. The authors also thank 
Professor Wen Jie and Dr Lin Gui-ping for their valuable help.

\section{References}

1. Lemiale V, Dumas F, Mongardon N, Giovanetti O, Charpentier J, Chiche JD, Carli P, Mira JP, Nolan J and Cariou A: Intensive care unit mortality after cardiac arrest: The relative contribution of shock and brain injury in a large cohort. Intensive Care Med 39: 1972-1980, 2013

2. McCook O, Radermacher P, Volani C, Asfar P, Ignatius A, Kemmler J, Möller P, Szabó C, Whiteman M, Wood ME, et al: H2S during circulatory shock: Some unresolved questions. Nitric Oxide 41: 48-61, 2014.

3. Luo Y, Yang X, Zhao S, Wei C, Yin Y, Liu T, Jiang S, Xie J, Wan $\mathrm{X}$, Mao M, et al: Hydrogen sulfide prevents OGD/R-induced apoptosis via improving mitochondrial dysfunction and suppressing an ROS-mediated caspase-3 pathway in cortical neurons. Neurochem Int 63: 826-831, 2013.

4. Wang Y, Jia J, Ao G, Hu L, Liu H, Xiao Y, Du H, Alkayed NJ, Liu CF and Cheng J: Hydrogen sulfide protects blood-brain barrier integrity following cerebral ischemia. J Neurochem 129 : 827-838, 2014

5. Zhang M, Shan H, Chang P, Wang T, Dong W, Chen X and Tao L: Hydrogen sulfide offers neuroprotection on traumatic brain injury in parallel with reduced apoptosis and autophagy in mice. PLoS One 9: e87241, 2014.

6. Jiang X, Huang Y, Lin W, Gao D, Fei Z, Chen X and Tao L: Protective effects of hydrogen sulfide in a rat model of traumatic brain injury via activation of mitochondrial adenosine triphosphate-sensitive potassium channels and reduction of oxidative stress. J Surg Res 184: e27-e35, 2013.

7. Zhang M, Shan H, Wang T, Liu W, Wang Y, Wang L, Zhang L, Chang P, Dong W, Chen X, et al: Dynamic change of hydrogen sulfide after traumatic brain injury and its effect in mice. Neurochem Res 38: 714-725, 2013.

8. Han Y, Qin J, Bu DF, Chang XZ, Yang ZX and Du JB: Gamma-aminobutyric acid $B$ receptor regulates the expression of hydrogen sulfide/cystathionine-beta-synthase system in recurrent febrile seizures. Zhongguo Dang Dai Er Ke Za Zhi 8: 141-143, 2006. (In Chinese).

9. Han Y, Qin J, Chang X, Yang Z, Bu D and Du J: Modulating effect of hydrogen sulfide on gamma-aminobutyric acid $\mathrm{B}$ receptor in recurrent febrile seizures in rats. Neurosci Res 53 . 216-219, 2005.

10. Markova J, Hudecova S, Soltysova A, Sirova M, Csaderova L, Lencesova L, Ondrias K and Krizanova O: Sodium/calcium exchanger is upregulated by sulfide signaling, forms complex with the $\beta 1$ and $\beta 3$ but not $\beta 2$ adrenergic receptors, and induces apoptosis. Pflugers Arch 466: 1329-1342, 2014.

11. Kimura Y and Kimura H: Hydrogen sulfide protects neurons from oxidative stress. FASEB J 18: 1165-1167, 2004.

12. Minamishima S, Bougaki M, Sips PY, Yu JD, Minamishima YA, Elrod JW, Lefer DJ, Bloch KD and Ichinose F: Hydrogen sulfide improves survival after cardiac arrest and cardiopulmonary resuscitation via a nitric oxide synthase 3 -dependent mechanism in mice. Circulation 120: 888-896, 2009.

13. Kida K, Minamishima S, Wang H, Ren J, Yigitkanli K, Nozari A, Mandeville JB, Liu PK, Liu CH and Ichinose F: Sodium sulfide prevents water diffusion abnormality in the brain and improves long term outcome after cardiac arrest in mice. Resuscitation 83: 1292-1297, 2012.

14. Derwall M, Westerkamp M, Löwer C, Deike-Glindemann J, Schnorrenberger NK, Coburn M, Nolte KW, Gaisa N, Weis J, Siepmann K, et al: Hydrogen sulfide does not increase resuscitability in a porcine model of prolonged cardiac arrest. Shock 34: 190-195, 2010.

15. Knapp J, Heinzmann A, Schneider A, Padosch SA, Böttiger BW, Teschendorf P and Popp E: Hypothermia and neuroprotection by sulfide after cardiac arrest and cardiopulmonary resuscitation. Resuscitation 82: 1076-1080, 2011

16. Qu K, Lee SW, Bian JS, Low CM and Wong PT: Hydrogen sulfide: Neurochemistry and neurobiology. Neurochem Int 52: 155-165, 2008

17. Lin JY, Liao XX, Li H, Wei HY, Liu R, Hu CL, Huang GQ, Dai G and Li X: Model of cardiac arrest in rats by transcutaneous electrical epicardium stimulation. Resuscitation 81: 1197-1204, 2010.
18. Idris AH, Becker LB, Ornato JP, Hedges JR, Bircher NG, Chandra NC, Cummins RO, Dick W, Ebmeyer U, Halperin HR, et al; Writing Group: Utstein-style guidelines for uniform reporting of laboratory CPR research. A statement for healthcare professionals from a task force of the American Heart Association, the American College of Emergency Physicians, the American College of Cardiology, the European Resuscitation Council, the Heart and Stroke Foundation of Canada, the Institute of Critical Care Medicine, the Safar Center for Resuscitation Research, and the Society for Academic Emergency Medicine. Circulation 94: 2324-2336, 1996.

19. Neumar RW, Bircher NG, Sim KM, Xiao F, Zadach KS, Radovsky A, Katz L, Ebmeyer E and Safar P: Epinephrine and sodium bicarbonate during CPR following asphyxial cardiac arrest in rats. Resuscitation 29: 249-263, 1995.

20. Lin JY, Wei HY, Li H, Li X, Liu R, Hu CL, Huang GQ, Dai G and Liao XX: Change of hydrogen sulfide content in serum of rats after cardiopulmonary resuscitation. Xi Bao Yu Fen Zi Mian Yi Xue Za Zhi 26: 363-365, 2010 (In Chinese).

21. Morris R: Developments of a water-maze procedure for studying spatial learning in the rat. J Neurosci Methods 11: 47-60, 1984.

22. Vorhees CV and Williams MT: Morris water maze: Procedures for assessing spatial and related forms of learning and memory. Nat Protoc 1: 848-858, 2006.

23. Feeney DM, Gonzalez A and Law WA: Amphetamine, haloperidol, and experience interact to affect rate of recovery after motor cortex injury. Science 217: 855-857, 1982.

24. Plaisier F, Bastide M, Ouk T, Pétrault O, Laprais M, Stolc S and Bordet R: Stobadine-induced hastening of sensorimotor recovery after focal ischemia/reperfusion is associated with cerebrovascular protection. Brain Res 1208: 240-249, 2008.

25. Gundersen HJ, Bendtsen TF, Korbo L, Marcussen N, Møller A, Nielsen K, Nyengaard JR, Pakkenberg B, Sørensen FB, Vesterby A, et al: Some new, simple and efficient stereological methods and their use in pathological research and diagnosis. APMIS 96: 379-394, 1988.

26. Li J, Han B, Ma X and Qi S: The effects of propofol on hippocampal caspase-3 and Bcl-2 expression following forebrain ischemia-reperfusion in rats. Brain Res 1356: 11-23, 2010.

27. Fink EL, Berger RP, Clark RS, Watson RS, Angus DC, Richichi R, Panigrahy A, Callaway CW, Bell MJ and Kochanek PM: Serum biomarkers of brain injury to classify outcome after pediatric cardiac arrest. Crit Care Med 42: 664-674, 2014.

28. Sulaj M, Saniova B, Drobna E and Schudichova J: Serum neuron specific enolase and malondialdehyde in patients after out-of-hospital cardiac arrest. Cell Mol Neurobiol 29: 807-810, 2009.

29. Stammet P, Wagner DR, Gilson G and Devaux Y: Modeling serum level of s100 $\beta$ and bispectral index to predict outcome after cardiac arrest. J Am Coll Cardiol 62: 851-858, 2013.

30. Kleindienst A, Hesse F, Bullock MR and Buchfelder M: The neurotrophic protein S100B: Value as a marker of brain damage and possible therapeutic implications. Prog Brain Res 161: 317-325, 2007.

31. Drabek T, Stezoski J, Garman RH, Wu X, Tisherman SA, Stezoski SW, Fisk JA, Jenkins L and Kochanek PM: Emergency preservation and delayed resuscitation allows normal recovery after exsanguination cardiac arrest in rats: A feasibility trial. Crit Care Med 35: 532-537, 2007.

32. Popp E, Padosch SA, Vogel P, Schäbitz WR, Schwab S and Böttiger BW: Effects of intracerebroventricular application of brain-derived neurotrophic factor on cerebral recovery after cardiac arrest in rats. Crit Care Med 32 (Suppl): S359-S365, 2004.

33. Cronberg T, Lilja G, Rundgren M, Friberg H and Widner H: Long-term neurological outcome after cardiac arrest and therapeutic hypothermia. Resuscitation 80: 1119-1123, 2009.

34. Meert KL, Donaldson A, Nadkarni V, Tieves KS, Schleien CL, Brilli RJ, Clark RS, Shaffner DH, Levy F, Statler K, et al; Pediatric Emergency Care Applied Research Network: Multicenter cohort study of in-hospital pediatric cardiac arrest. Pediatr Crit Care Med 10: 544-553, 2009.

35. Schreckinger M, Geocadin RG, Savonenko A, Yamashita S, Melnikova T, Thakor NV and Hanley DF: Long-lasting cognitive injury in rats with apparent full gross neurological recovery after short-term cardiac arrest. Resuscitation 75: 105-113, 2007.

36. Garthe A and Kempermann G: An old test for new neurons: Refining the Morris water maze to study the functional relevance of adult hippocampal neurogenesis. Front Neurosci 7: 63,2013 . 
37. Tahamtan M, Allahtavakoli M, Abbasnejad M, Roohbakhsh A Taghipour Z, Taghavi M, Khodadadi $\mathrm{H}$ and Shamsizadeh A: Exercise preconditioning improves behavioral functions following transient cerebral ischemia induced by 4-vessel occlusion (4-VO) in rats. Arch Iran Med 16: 697-704, 2013.

38. Tamakoshi K, Ishida A, Takamatsu Y, Hamakawa M, Nakashima H, Shimada H and Ishida K: Motor skills training promotes motor functional recovery and induces synaptogenesis in the motor cortex and striatum after intracerebral hemorrhage in rats. Behav Brain Res 260: 34-43, 2014.

39. Zhang H, Sun R, Liu XY, Shi XM, Wang WF, Yu LG and Guo XL: A tetramethylpyrazine piperazine derivate CXC137 prevents cell injury in SH-SY5Y cells and improves memory dysfunction of rats with vascular Dementia. Neurochem Res 39: 276-286, 2014.
40. Thal SC, Mebmer K, Schmid-Elsaesser R and Zausinger S: Neurological impairment in rats after subarachnoid hemorrhage - a comparison of functional tests. J Neurol Sci 268: 150-159, 2008.

41. Szabó C: Hydrogen sulphide and its therapeutic potential. Nat Rev Drug Discov 6: 917-935, 2007.

42. Zhang LM, Jiang CX and Liu DW: Hydrogen sulfide attenuates neuronal injury induced by vascular dementia via inhibiting apoptosis in rats. Neurochem Res 34: 1984-1992, 2009.

43. DeMaster EG, Raij L, Archer SL and Weir EK: Hydroxylamine is a vasorelaxant and a possible intermediate in the oxidative conversion of L-arginine to nitric oxide. Biochem Biophys Res Commun 163: 527-533, 1989.

44. Chao CC, Hu S, Molitor TW, Shaskan EG and Peterson PK: Activated microglia mediate neuronal cell injury via a nitric oxide mechanism. J Immunol 149: 2736-2741, 1992. 